\title{
Correction to "Energy dissipation in multifrequency atomic force microscopy"
}

\author{
Valentina Pukhova ${ }^{1,2}$, Francesco Banfi ${ }^{2}$ and Gabriele Ferrini ${ }^{*}$
}

\section{Correction}

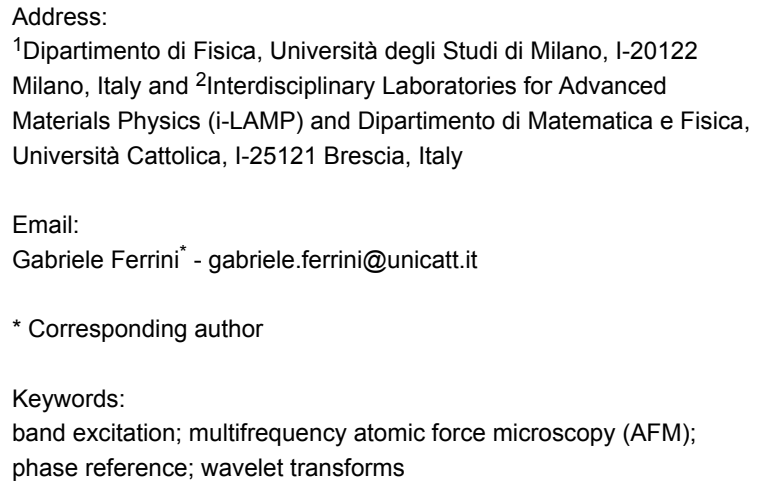

${ }^{1}$ Dipartimento di Fisica, Università degli Studi di Milano, I-20122 Milano, Italy and ${ }^{2}$ Interdisciplinary Laboratories for Advanced Materials Physics (i-LAMP) and Dipartimento di Matematica e Fisica, Università Cattolica, I-25121 Brescia, Italy

Email:

Gabriele Ferrini* - gabriele.ferrini@unicatt.it

* Corresponding author

Keywords:

band excitation; multifrequency atomic force microscopy (AFM);

phase reference; wavelet transforms

Beilstein J. Nanotechnol. 2014, 5, 667. doi:10.3762/bjnano.5.78

Received: 14 May 2014

Accepted: 14 May 2014

Published: 20 May 2014

This article is part of the Thematic Series "Noncontact atomic force microscopy II".

Guest Editors: U. D. Schwarz and M. Z. Baykara

(C) 2014 Pukhova et al; licensee Beilstein-Institut. License and terms: see end of document.

This correction refers to Beilstein J. Nanotechnol. 2014, 5, 494-500. doi:10.3762/bjnano.5.57

In the section "Energy dissipation" of the above manuscript, there is a typesetting error in the mathematical expressions after Equation 5. The correct form must be:

The energy balance of each decaying mode obtained from Equation 4 in the time window $0<t<\tau=200 \mu$ s (see Figure 1) can be written as

$$
E_{b_{i}}=E_{\gamma_{i}}
$$

where

$$
\begin{aligned}
& E_{b_{i}}=\Delta K_{i}+\Delta U_{i} \\
& E_{\gamma_{i}}=\int_{0}^{\tau} m_{\mathrm{eq}} \gamma_{i} v_{i}^{2} d t
\end{aligned}
$$

$i$ is the index of the mode, $\Delta K_{i}=1 / 2 m_{\mathrm{eq}}\left(\mathrm{v}_{i}(0)^{2}-\mathrm{v}_{i}(\tau)^{2}\right)$ is the variation of kinetic energy, and $\Delta U_{i}=1 / 2 k_{i}\left(z_{i}(0)^{2}-z_{i}(\tau)^{2}\right)$ is the variation of elastic potential energy.

\section{License and Terms}

This is an Open Access article under the terms of the Creative Commons Attribution License (http://creativecommons.org/licenses/by/2.0), which permits unrestricted use, distribution, and reproduction in any medium, provided the original work is properly cited.

The license is subject to the Beilstein Journal of Nanotechnology terms and conditions: (http://www.beilstein-journals.org/bjnano)

The definitive version of this article is the electronic one which can be found at: doi:10.3762/bjnano.5.78 